\title{
Willingness to pay to improve air quality: a study of private vehicle owners in Klang Valley, Malaysia
}

\begin{abstract}
The growing number of private passenger vehicles in the Klang region of Malaysia has not only resulted in persistent traffic congestion during peak hours, but also resulted in considerable vehicular emissions causing both environmental and human health hazards. To reduce these externalities, this study examines the prospect for a transport modal shift from the use of private vehicles to the public transport system. Contingent valuation method was used to estimate how much current private passenger vehicle users are willing to pay to continue using their private vehicles. On average, private passenger vehicle users were found to be willing to pay a maximum amount of RM 4.99 (USD 1.55) per trip to avoid using the public transport system. Respondents with previous health issues were found more likely to shift to the public transportation system. Public transportation efficiency was found to have a significant impact on the respondents WTP value to maintain the current commuting system.
\end{abstract}

Keyword: Environmental awareness; Transportation pollution; Economic valuation; Willingness to pay; Contingent valuation 